\title{
Integrated care services for Romanian HIV/HCV co-infected patients from key populations - lessons learned from HepCare Europe Project experience in Bucharest clinical site
}

\author{
Irina Ianache' ${ }^{1}$, Stefan Lazar', Ionut Popa', Alma Kosa', Anca Luca ${ }^{1}$, Ioan Petre', \\ Simin Florescu ${ }^{1,2}$, Cristiana Oprea ${ }^{1,2}$ \\ 1"Dr. Victor Babes" Clinical Hospital of Infectious and Tropical Diseases, Bucharest, Romania \\ 2"Carol Davila" University of Medicine and Pharmacy, Bucharest, Romania
}

\begin{abstract}
Background. HepCare Europe was a project co-funded by the European Commission with the scope to create and implement a model of HCV management (screening, linkage to care, treatment) for patients from key populations, through outreaching the community and to offer integrated primary and secondary care services. The aim of this sequential research inside the project was to evaluate the socio-demographic and clinical characteristics of HIV/HCV co-infected patients enrolled in HepCare Europe Project at Bucharest clinical site and to compare them to HCV-mono-infected patients.

Methods. Prospective study on patients who tested positive for HCV antibodies (using rapid oral tests), part of them being linked to care at "Dr. Victor Babes" Clinical Hospital Bucharest, Romania (SVB), between April 2016 and April 2019. Socio-demographic and clinical characteristics of patients linked to care were compared according to their HIV status. Statistical analysis was performed using SPSS vs. 20.0.

Results. A total of 525 patients were screened for HCV antibodies using rapid oral tests, out of which $230(43.8 \%)$ tested positive. Almost all of them were young males $(85.2 \%)$ and injecting drug users (IDUs) $(92.2 \%) .168$ patients $(73.0 \%)$ were linked to care, with $41.6 \%$ being coinfected with HIV. Liver fibrosis assessment was performed in $82.1 \%$ patients, almost a third of them having advanced liver fibrosis $(27.5 \%)$. Plasma HCV-RNA was performed for half of the patients linked to care and $80.9 \%$ were detectable. Directing acting antivirals (DAA) treatment was initiated in 24 patients out of which 22 achieved SVR (sustained virological response) and 2 were non-responders (IDUs with genotype 3 treated with non-pan genotypic regimens). HIV-infection was associated with homelessness $(p<0.0001)$, injecting drug use $(p=0.001)$, NPS (new psychoactive substances) use in combination with opioids $(p<0.0001)$, needle sharing $(p<0.0001)$ and alcohol abuse $(p<0.0001)$. The median CD4 cell count $(/ \mu \mathrm{l})$ and median plasma HIV-RNA (log10copies $/ \mathrm{ml}$ ) were 483 (IQR 290, 646) and 2.74 (IQR 1.27, 4.67), respectively. HCV-RNA was significantly higher in HIV/ HCV co-infected patients $(p=0.047)$.

Conclusions. HIV/HCV co-infection was high among patients from key populations. HIV infection was associated with multiple risk factors and higher HCV-RNA. Socio-economic barriers and the lack of pan genotypic DAAs limited the treatment and outcomes in this group. This is the first pilot study on managing patients with HCV from key population in Romania.
\end{abstract}

Keywords: HIV/HCV co-infection, HepCare Europe, key populations, DAA

\section{BACKGROUND}

Chronic hepatitis $\mathrm{C}(\mathrm{HCV})$ infection represents one of the most important causes of mortality and morbidity worldwide. The most severe complications are liver cirrhosis and hepatocellular carcino- ma (HCC). It is estimated that approximately $3 \%$ of the world population is affected by $\mathrm{HCV}$ infection $(1,2)$.

Sero-prevalence of HCV in Romania is estimated to be around $3.23 \%$, with $2.72 \%$ viremic pa- 
tients. Studies performed before 2009 suggested that the most prevalent genotype in our country is genotype b (99\%), most often acquired through blood transfusion before 1993, or unsafe medical procedures in the late ' 80 . The epidemiology of $\mathrm{HCV}$ in Romania was changed during last decade due to the significant increase in injecting drug use, associated with the spread of new HCV genotypes. In addition to opioids, new psychoactive drugs (NPS), locally known as "ethnobotanicals", were frequently used, being cheaper and therefore more affordable for most injecting drug users. These drugs are highly addictive and have a short life time, requiring up to $10-20$ administrations per day $(1,3,4)$.

HIV and HCV epidemics among IDUs from Romania were favored by the frequent use of psychoactive injectable drugs. It was also a risk factor for dissemination of new HCV genotypes (different from 1b) in the general population, with lower rates of response to treatment with. In addition, it is a well-known fact that $\mathrm{HIV} / \mathrm{HCV}$ co-infection is associated with accelerated liver fibrosis and higher rates of hepatic decompensations, comparing to HCV-mono-infection (1,3-5).

Injecting drug users are still a major challenge for the Romanian health care system, due to their high-risk behaviors, neuro-psychiatric disorders and multiple comorbidities, as well as social issues (homelessness, lack of health insurance or identity documents).

HepCare Europe is a project co-funded by the European Commission whose aim was to create and implement a model of HCV management (screening, linkage to care and treatment) for patients from key populations, through outreach to the community and integrated primary and secondary care services. It is a consortium between 5 institutions from 4 countries (Ireland, United Kingdom, Spain and Romania) (6).

The project was based on 5 interconnected work packages (WP) developed in order to optimize HCV management among patients from key populations (Figure 1) (5).

1. HepCheck - HCV antibodies screening using rapid oral tests (OraQuick)

$\mathrm{HCV}$ testing was performed using point-of care tests, with the help of stakeholders from the community (social workers from NGOs, local staff from night shelters, HCPs (health care providers) from prisons, opioid substitution centers) or GPs (general practitioners). All patients who were tested were enrolled in HepCare project database and a questionnaire regarding their lifestyles, risk factors for $\mathrm{HCV}$ and their medical history was completed.

2. HepLink - linkage to care by integrating primary and secondary care services

Patients who tested positive within the previous WP were referred to the infectious diseases specialist for liver fibrosis staging and HCV-RNA testing. DAA treatment was initiated in case of eligibility. All patients who were linked to care were enrolled in HepLink database, containing information about their blood tests and fibrosis evaluation results.

3. HepEd - inter-professional education

$\mathrm{HCV}$ educational masterclasses were organized in order to provide updated information about $\mathrm{HCV}$ management in patients from key populations. These events targeted HCPs, mainly GPs but also specialist physicians (infectious diseases, psychiatrist, gastroenterologist etc.), as well as nurses, social workers and psychologists. Pre and post course evaluation questionnaires were used in order to evaluate the efficiency of these masterclasses.

4. HepFriend - peer support programs

HepFriend was based on recruitment of persons from the community, with lifestyles similar to persons from targeted populations. The aim was to train and support them on improving the collaboration between patients and HCPs. Peers were also involved in peer support meeting organization, in order to improve adherence to treatment and retention in care.

5. HepCost - estimation of cost-efficiency of model implementation

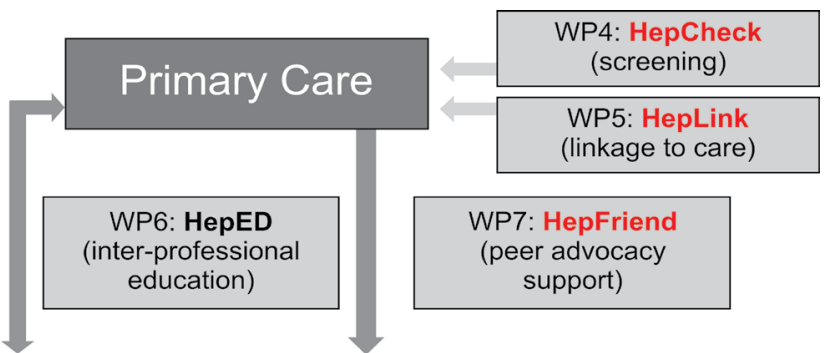

Secondary Care

WP8: HepCost

WP 1 Coordination; WP 2 Dissemination; WP 3 Evaluation

FIGURE 1. HepCare Europe Project - Work Packages 
The aim of our study was to evaluate the sociodemographic and clinical characteristics of HIV/ $\mathrm{HCV}$ co-infected patients enrolled in HepCare Europe Project at Bucharest clinical site, and to compare them to HCV-mono-infected patients.

\section{METHODS}

We performed a prospective study on patients who tested positive for HCV antibodies (using rapid oral tests), and linked to care at Victor Babes Hospital, Bucharest (SVB), between April 2016 and April 2019. Socio-demographic and clinical characteristics of patients linked to care were compared according to their HIV status.

Rapid oral antibody tests (OraSure Technologies OraQuick HCV) were used for screening. It was provided in 9 sites involved in medical and social services for targeted population ( 3 night-shelters, 3 opioid substitution treatment centers, 2 prisons and 1 health care facility), as well as in GPs practices or by personnel from NGOs who went in the community and tested. Pre and post testing counselling were also offered, as well as information about the project and its aims. Each patient signed an inform consent, answered a few questions about their lifestyles and medical history and also provided their contact details. Those who tested positive were linked to care at SVB.

Blood tests including HCV antibodies and plasma HCV-RNA were tested in order to confirm the $\mathrm{HCV}$ infection. Liver fibrosis assessment was performed by Fibro Scan or by FibroMax. Advanced liver fibrosis was considered in patients with a METAVIR score above $9 \mathrm{kPa}$.

Statistical analysis was performed using SPSS vs. 20.0. Chi-square or Fisher's exact tests were used for categorical data and t-test or One-Way Anova test for continuous variables. A p-value < 0.05 was considered statistically significant.

\section{RESULTS}

During the study period, 525 patients were screened for HCV antibodies with rapid oral tests, out of which $228(43.4 \%)$ were active or former injecting drug users. 230 (43.8\%) subjects tested positive for $\mathrm{HCV}$. The percentage of positive $\mathrm{HCV}$ antibodies was higher in patients admitted in the infectious disease hospital and in opioid substitution centers, compared to those from prisons and night shelters $(p<0.0001)$ (Figure 2$)$.

The majority of $\mathrm{HCV}$ positive patients were males $85.2 \%(196 / 230)$, with a median age 35 years (IQR 31, 39). Almost all of them were injecting drug users and a third of them were also alcohol users (Table 1).

A total of $168 / 230$ patients $(73.0 \%)$ were linked to care, out of which $41.6 \%(70 / 168)$ were also coinfected with HIV. HIV-infection was more often associated with homelessness $(\mathrm{p}<0.0001)$, injecting drug use $(\mathrm{p}=0.001)$, NPS use in combination with opioids ( $<<0.0001)$, needle sharing $(p<0.0001)$ and alcohol abuse $(\mathrm{p}<0.0001)$ (Table 1$)$. The median CD4 cell count $(/ \mu 1)$ and median plasma HIV-RNA $(\log 10$ copies $/ \mathrm{ml})$ were 483 (IQR 290, 646) and 2.74 (IQR 1.27, 4.67), respectively.

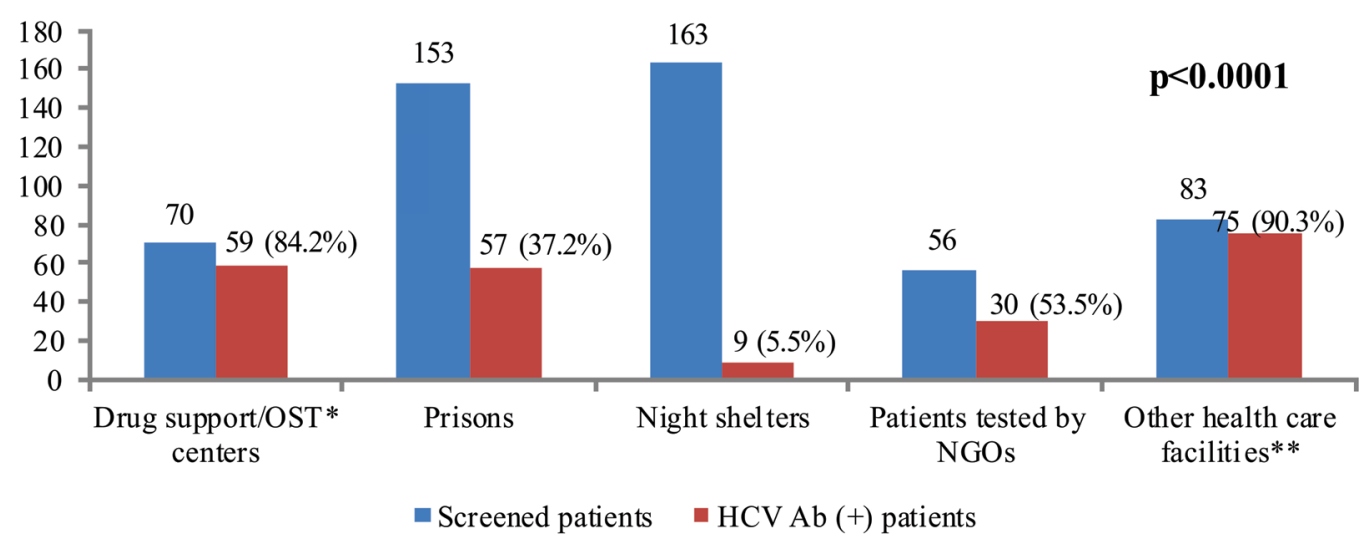

FIGURE 2. Proportion of patients with positive result at HCV antibodies screeningcomparison between screening sites

${ }^{*}$ OST = opioid substitution treatment ${ }^{* *}$ mainly IDUs admitted at infectious diseases hospital 
TABLE 1. Social characteristics of patients linked to care comparison between HIV-positive and HIV-negative patients

\begin{tabular}{|l|c|c|c|c|c|}
\hline & & $\begin{array}{c}\text { Total } \\
\mathbf{n = 1 6 8}\end{array}$ & $\begin{array}{c}\text { HIV (+) } \\
\mathbf{n = 7 0}\end{array}$ & $\begin{array}{c}\text { HIV (-) } \\
\mathbf{n = 9 8}\end{array}$ & p value \\
\hline Homelessness & $\mathrm{n}(\%)$ & $61(36.3)$ & $37(52.8)$ & $24(24.4)$ & $<0.0001$ \\
\hline Imprisonment & $\mathrm{n}(\%)$ & $89(52.9)$ & $42(60.0)$ & $47(47.9)$ & 0.83 \\
\hline OST* & $\mathrm{n}(\%)$ & $85(50.5)$ & $32(45.7)$ & $53(54.0)$ & 1.81 \\
\hline IDUs & $\mathrm{n}(\%)$ & $155(92.2)$ & $70(100)$ & $85(86.7)$ & 0.001 \\
\hline Sharing needles & $\mathrm{n}(\%)$ & $82(48.8)$ & $51(72.8)$ & $31(31.6)$ & $<0.0001$ \\
\hline Type of drug & & & & & \\
Heroin & $\mathrm{n}(\%)$ & $30(17.8)$ & $7(10.0)$ & $24(24.4)$ & \\
NPS** & & $57(33.9)$ & $16(22.8)$ & $42(42.8)$ & $<0.0001$ \\
Mixed abuse & $73(43.3)$ & $51(72.8)$ & $24(24.4)$ & \\
\hline Alcohol abuse & $\mathrm{n}(\%)$ & $67(39.8)$ & $41(58.5)$ & $26(26.5)$ & $<0.0001$ \\
\hline
\end{tabular}

${ }^{*}$ OST = opioid substitution treatment; ${ }^{* *}$ NPS = new psychoactive stimulants

Liver fibrosis assessment was performed in $82.1 \%(138 / 168)$ patients, almost a third of them having advanced liver fibrosis (27.5\%). Plasma HCV-RNA was performed in $50 \%$ of the patients linked to care (84/168), 68 (80.9\%), being detectable. HCV-RNA was significantly higher in HIV/ HCV co-infected patients ( $p=0.047)$. HBV co-infection was also more common in HIV-coinfected patients (Table 2).

Within the HepEd work package, $3 \mathrm{HCV}$ Masterclasses with updated information about the management of chronic hepatitis $\mathrm{C}$ were organized by the HepCare team and were attended by 241 HCPs. Booklets and flyers with basic information on epidemiology and treatment of $\mathrm{HCV}$ infection were created and disseminated to patients from key populations.

Peer support sessions were attended by $64 \mathrm{HIV} /$ HCV coinfected patients, as part of the HepFriend work package.
DAA treatment was initiated in 24 patients, 17 of them being HIV positive. SVR (sustained virological response) was obtained in 22 patients and 2 were non-responders, both of them being HIV coinfected IDUs, with genotype 3.

\section{DISCUSSION}

HepCare Europe is the first project focused on patients from key populations in our country, which tried to implement a model of $\mathrm{HCV}$ care, based on the principle of integrated primary and secondary care services, as well as outreach to the community (5). Bucharest clinical site was involved in all WP of the project.

HCV screening was performed in districts from Bucharest accessed frequently by patients from key populations, such as night shelters, opioid substitution treatment centers, prisons or health care facilities. GPs responsible for each screening site were

TABLE 2. Laboratory findings- comparison between HIV/HCV co-infected and HCV mono-infected patients linked to care

\begin{tabular}{|c|c|c|c|c|c|}
\hline & & $\begin{array}{c}\text { Total } \\
n=168\end{array}$ & $\begin{array}{c}\text { HIV (+) } \\
n=70\end{array}$ & $\begin{array}{c}H I V(-) \\
n=98\end{array}$ & $p$ value \\
\hline $\begin{array}{l}\text { ALT } \\
\text { (IU/L) }\end{array}$ & $\begin{array}{c}\text { median } \\
\text { (IQR) }\end{array}$ & $\begin{array}{c}63 \\
(40,98)\end{array}$ & $\begin{array}{c}65 \\
(43,100)\end{array}$ & $\begin{array}{c}58 \\
(34,97)\end{array}$ & 0.866 \\
\hline $\begin{array}{l}\text { Hemoglobin } \\
(\mathrm{g} / \mathrm{dl})\end{array}$ & $\begin{array}{c}\text { median } \\
\text { (IQR) }\end{array}$ & $\begin{array}{c}14.1 \\
(12.9,15.3)\end{array}$ & $\begin{array}{c}13.7 \\
(12.5,14.9)\end{array}$ & $\begin{array}{c}15.0 \\
(13.6,15.7)\end{array}$ & 0.080 \\
\hline $\begin{array}{l}\text { Platelets* } 10^{3} \\
(/ \mu \mathrm{L})\end{array}$ & $\begin{array}{c}\text { median } \\
\text { (IQR) }\end{array}$ & $\begin{array}{c}224 \\
(174,261)\end{array}$ & $\begin{array}{c}225 \\
(167,257)\end{array}$ & $\begin{array}{c}215 \\
(188,261)\end{array}$ & 0.640 \\
\hline HBs Ag positive & n (\%) & $\begin{array}{c}13 \\
(7.7)\end{array}$ & $\begin{array}{c}9 \\
(12.8) \\
\end{array}$ & $\begin{array}{c}4 \\
(4.0)\end{array}$ & 0.011 \\
\hline $\begin{array}{l}\text { Fibrosis stage } \\
\text { (METAVIR score) }\end{array}$ & $\begin{array}{c}\text { median } \\
\text { (IQR) }\end{array}$ & $\begin{array}{c}7.0 \\
(5.4,9.3)\end{array}$ & $\begin{array}{c}7.0 \\
(6.0,9.5)\end{array}$ & $\begin{array}{c}7.0 \\
(5.3,9.3)\end{array}$ & 0.372 \\
\hline HCV-RNA $\left(\log _{10} I U / L\right)$ & $\begin{array}{c}\text { median } \\
\text { (IQR) }\end{array}$ & $\begin{array}{c}6.11 \\
(5.48,6.52)\end{array}$ & $\begin{array}{c}6.30 \\
(5.77,6.66)\end{array}$ & $\begin{array}{c}5.50 \\
(5.16,5.88)\end{array}$ & 0.047 \\
\hline
\end{tabular}


involved in $\mathrm{HCV}$ testing, in collaboration with HepCare team and the social workers from NGOs, partners of SVB. Subjects who tested HCV positive were scheduled for linkage to care at „Victor Babes" Hospital, in order to integrate primary and secondary care services for persons from key populations.

Patients from key populations, mainly injecting drug users, are a major challenge for the Romanian health care system, due to multiple social, medical and economic issues (5). HCV and HIV were spread rapidly among Romanian IDUs, secondary to the dynamics on the illegal drugs market characterized by the significant increase of NPS use. Being more affordable comparing to heroin, a high number of IDUs tried to get free of the addiction to opioids, by switching to NPS use, but failed and became addicted to both drugs (3). Ethnobotanical drugs are cathinone derived and have psychoactive effects similar to those produced by amphetamines. They are cheaper than heroine, but because of the important addiction they require multiple injections per day. IDUs used unsterile injection equipment and shared syringes and needles that lead to an uncontrolled spread of blood borne viral infections among them $(3,7)$.

The profile of the patients screened for $\mathrm{HCV}$ within HepCare Project using rapid oral tests is of a young injecting drug male, with multiple high-risk behaviors (alcohol abuse or history of homelessness and imprisonment).

Patients from key populations, who tested HCV positive, had to face multiple social barriers in order to be linked to care. The majority of them were homeless, former prisoners, without occupation, health insurance or identity documents. The process to obtain these documents was complicated and a high number of them were lost to follow-up (3). It was more difficult to link to care prisoners, because of some barriers in evaluating them in the hospital during imprisonment. There were also patients who didn't respect the appointments at SVB for investigations, and were difficult to reach. Social workers from NGOs facilitated the procurement of the documents for homeless people and IDUs to be able to be included in the National Program for HCV treatment.

Almost half of the patients linked to care within HepCare Europe Project were co-infected with
HIV and a lower proportion were coinfected also with HBV. HIV infection was more often associated with NPS use and sharing needles, as well as with HBV infection and higher levels of plasma HCV-RNA.

DAA treatment was initiated only in few patients enrolled in the project, due to multiple disease and social barriers. In addition, a high number of patients avoid to access medical services, being afraid that they will be rejected. However, HIV coinfection was not a problem in treating $\mathrm{HIV} / \mathrm{HCV}$ co-infected patients from our database. All of them were really enthusiastic to initiate treatment and were adherent.

DAA treatment became available in Romania in 2015. Initially there were multiple disease barriers, DAA treatment being available only for patients with advanced liver fibrosis (F3, F4). Starting with September 2018, DAA treatment became available for patients with liver fibrosis $\geq$ F1 METAVIR. Due to the fibrosis restrictions not all the patients from our database were eligible for treatment. At the end of year 2019 The National Protocol for HCV treatment was updated, disease barriers were removed and HCV infected patients will be treated irrespective of the fibrosis stage.

The absence of pan-genotypic regimens in our country was also a factor that contributes to treatment failure in 2 of the patients. In addition, $\mathrm{HCV}$ genotyping before treatment is not usually performed in Romania. Injecting drug use was associated with the spread of new HCV genotypes (1a, 3, 4) associated with accelerated liver fibrosis and with lack of response to available DAA regimen $(4,8)$. Genotyping performed after treatment failure in patients with no SVR showed HCV genotype 3 in both cases. However, $22 \mathrm{HCV}$ infected IDUs were treated successfully and this is a very promising start in the fight for HCV elimination in key population in our country.

Estimation of the cost-efficiency of the implementation of the model is still under evaluation.

Injecting drug users who were diagnosed with $\mathrm{HCV}$ and linked to care within the HepCare project, and were not eligible for DAA treatment until the end of year 2019, could benefit of treatment in the near future, due to the new regulations in the National HCV protocol, with the remove of all the disease and laboratory barriers. 


\section{CONCLUSIONS}

HCV elimination will be possible only if patients from key populations will be treated successfully. In the capital city there is still a large pool of patients with high risk behaviors and their access to DAA treatment is still difficult due the persistence of social barriers. It is important to start with $\mathrm{HCV}$ micro-elimination in patients from key populations. Micro-elimination of $\mathrm{HCV}$ in key population, will lead to an important decrease in new $\mathrm{HCV}$ cases and will consecutively reduce the spread of the disease.

The HepCare model used at Victor Babes Hospital site showed its efficacy and therefore it should be implemented on a larger scale.

Conflict of interest: none declared Financial support: none declared

\section{REFERENCES}

1. Gheorghe L, Sporea I, lacob S, Sirli R, Trifan A, Dobru D et al. Position paper on treatment of hepatitis $C$ in Romania, 2017. Part one. Journal of Gastrointestinal and Liver Diseases 2017; 26(2):171-81.

2. Esteban JI, Sauleda S, Quer J. The changing epidemiology of hepatitis $C$ virus infection in Europe. Journal of Hepatology. 2008;48(1):148-62.

3. Oprea C, lanache I, Calistru PI, Nica M, Ruta S, Smith C et al. Increasing incidence of HIV-associated tuberculosis in Romanian injecting drug users. HIV medicine. 2018; 19(5):316-23.

4. Ruta S, Sultana C, Oprea C, Vagu C, Ceausu E, Cernescu C. HCV non-1b genotypes in injecting drug users from Romania. Journal of Infection in Developing Countries. 2016; 10(5):523-7.

5. Swan D, Cullen W, Macias J, Oprea C, Story A, Surey J et al. HepCare Europe - bridging the gap in the treatment of hepatitis $C$ :
Study protocol. Expert Review of Gastroenterology \& Hepatology. 2018; 12(3):303-14.

6. Avramovic G, Oprea C, Surey J, Story A, Macias J, Cullen W et al. HepCheck: Characteristics of the patient population with active infection as defined by HCV RNA. International Journal of Infectious Diseases (official publication of the International Society for Infectious Diseases). 2019.

7. Ianache I, Calistru P, Tardei G, Ruta S, Oprea C. Late presentation in HIV-infected injecting drug users - a huge challenge for the Romanian health-care system. Romanian Journal of Legal Medicine. 2016; 24(2):122-7.

8. McPhee F. Developments in the treatment of HCV genotype 3 infection. Expert Review of Anti-infective Therapy. 2019; 17(10):775-85. 